\title{
FEATURES OF THE ORGANISATION OF ROOTING CUTTINGS OF DECORATIVE WOODY PLANTS UNDER ARTIFICIAL LIGHTING WITH LED EQUIPMENT
}

\author{
${ }^{a} A n d r e i$ M. Piatykh*, bMikhail A. Emelianov, aAleksandr V. Akinchin, aIvan V. Partolin, bAlla A. Belyaeva \\ aBelgorod State Agricultural University named after V. Gorin, Mayskiy, Russian Federation. \\ ${ }^{b}$ LLC "Gelan", Belgorod, Russian Federation.
}

ART ICLE INF O

\section{Article History}

Received: April 21, 2021

Revised: July 1, 2021

Accepted: July 30, 2021

\section{Keywords}

Spectrum

LED

Cutting

Sprouts root systems

Planting material

Phytopathological

monitoring

\section{A B S T R A C T}

Obtaining a technology for rooting cuttings and standard seedlings of decorative woody plants under artificial lighting conditions is relevant in connection with the need to increase the amount of planting material required for green building. Currently, cuttings are carried out mainly in greenhouses during the growing season. The development of technology for rooting cuttings using lamps with different lighting parameters opens up the possibility of creating installations that are effective in various conditions. In the course of the study, organisational and technological measures were taken to modernise the greenhouse and install equipment for growing planting material of decorative plants. In accordance with the plan to study the characteristics of various crops using the technology of dynamic regulation of the spectral composition and temporal characteristics of LED lighting in a greenhouse, an assortment of decorative tree species has been developed. Heated greenhouses are equipped with automatic irrigation hotbeds. Cutting of coniferous, deciduous, fast- and slow-growing species of decorative woody plants ( 7 species and 3 cultivars in total) was carried out. Rooting was carried out under illumination with batch-type LED installations. The success of rooting is studied when using LEDs of various production, with different spectral composition and varying illumination intensity during year-round cultivation. The findings are necessary not only for the development of a regional technology for the year-round production of rooted cuttings of decorative woody plants, but also for the development of the engineering specifics of lighting equipment.

Corresponding Author: Andrei M. Piatykh

Email: ampiatykh6652@ubogazici.in

(c) The Author(s) 2021.

\section{INTRODUCTION}

Modern standards for the level of comfort in the urban environment require the development of a system for greenspace expansion. In this regard, work on the creation of green spaces for various purposes is expanding in the Russian Federation. To improve the comfort of the urban environment, it is planned to reconstruct the existing urban green spaces, as well as to create new squares, parks and city gardens. Much attention is paid to the laying of street alleys and landscape compositions. In the Belgorod Oblast, a number of regional programmes for the improvement and landscaping of public spaces of settlements have been introduced. Works on the design and construction of various objects of landscape architecture are relevant not only for the Black Earth region, but also for the Russian Federation as a whole (Pyatih et al., 2019; Selivanova and Kartashova, 2016; Teodoronskiy and 
Zherebtsova., 2010). To implement these plans, it is necessary to expand the production of standard planting material, which is adapted not only to growing conditions, but also to the urban environment. Particular attention should be paid to organising the cloning of the most valuable decorative woody plants throughout the year, which increases the success of the breeding departments of greenhouse complexes. The efficiency of obtaining a standard planting material for woody plants largely depends on the lighting conditions, especially in the autumn-winter period. To develop a technology for year-round production of rooted cuttings, the study of the effect of artificial lighting with LED (light-emitting diode) lighting equipment on the success of rooting and obtaining a standard planting material for decorative woody plants has begun (Efremova et al., 2020; Kozlowski and Pallardy, 2002).

Light is one of the main environmental factors in plant life and controls almost all physiological and biochemical processes in the plant body (Nissim-Levi et al., 2019). Growing plants in laboratories and greenhouses requires the selection of modern energy efficient light sources such as LEDs. With the help of LEDs, it is possible to design light sources with a certain spectral composition of light for specific plant species and stages of their development (Bakharev et al., 2019; Morrow, 2008). Thus, one of the important factors influencing the successful adaptation and growth of regenerative plants transplanted ex vitro is the optimal spectral composition and light intensity. For a long time, artificial lighting of plants was carried out using halogen, gas-discharge lamps and even fluorescent lamps. The main disadvantage of these light sources is the strong heat radiation, which negatively affects the plants. Overheating leads to disruption of photosynthetic processes, decreased $\mathrm{CO}_{2}$ absorption, thermal burns and excessive moisture evaporation.

With the development of LED technology, the so-called full spectrum grows lamps appeared and quickly gained popularity in the lighting market. Designed as a replacement for HID (high-intensity discharge) lamps, they were widely used in greenhouses. Despite the fact that these lamps are focused on spectral ranges that affect all stages of plant development, which can increase productivity (root development, flowering, fruiting, green mass growth, etc.), they revealed significant drawbacks in the growing process. One of the most significant was the predominance of the red dominant in the spectrum, which coloured the emitted light in a bright pink colour. Such lighting with the use of potassium permanganate is not optimal for plants or agronomists, makes it difficult for people to work, causes headaches, fatigue and practically excludes the possibility of an adequate visual inspection of plants. LED plant lights are in demand in hydroponics because of the physical properties of LEDs, which allow for the accurate selection the light spectrum with a wavelength that provides the most favourable conditions for the growth and fruiting of plants. The most favourable conditions for photosynthesis have been created, plants grow faster and healthier. LED plant light can be applied anywhere and in a range. Due to their unique nature, low energy consumption and low temperature, LEDs promote plant growth. This is not only an economical solution, but also increases the ability of farmers to control plant growth. However, there are problems with adjusting the size of existing LED lights to suit the unique needs of plants, depending on their type and size. With the distribution of potassium permanganate, lamps with traditional light sources (halogen, metal halide, and fluorescent) continue to be used, while full spectrum LED lamps are not widely adopted yet. Such different approaches to lighting decorative plants and the low popularity of full spectrum LED light sources prompted this study.

To compare the effects of different light sources on decorative plants, an experiment was conducted to study the effects of light on plants. As a result of the experiment, results were obtained that confirmed that ready-made LED modules can be used to illuminate plants. The best results are obtained with a white spectrum LED module, but with an improved violet range. Thus, the possibility of illuminating decorative plants with full-spectrum LED light sources has been experimentally confirmed.

\section{MATERIALS AND METHODS}

The hotbeds have been built in the static greenhouses of the municipal budgetary institution Department of Belgorbplagustroystvo. The drip irrigation system was installed. Installation of pilot lighting installations for cuttings has been completed. Cutting of decorative tree species was carried out in experimental cassettes, which were placed in accordance with the experimental design. The first results of the influence of the light-controlled cultivation of decorative plants in protected ground conditions in the autumn period were obtained using the example of fast-growing species (Figure 1). 


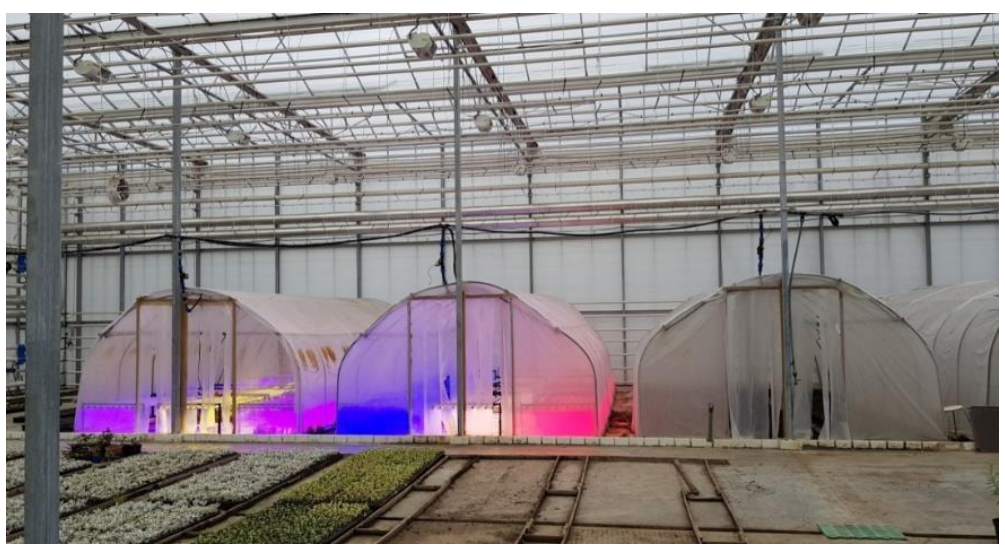

Figure 1. Experimental hotbeds for cuttings under artificial lighting with LED equipment.

Efficient and economical controlled LED lighting installations, controlled spectrum of photon flux and photoperiod control in protected ground conditions have been created. For additional illumination of plants, lamps were used using light-emitting diodes as a light source. A light-emitting diode, is a semiconductor device that emits optical radiation when a current is passed through it in the forward direction. Currently, several technologies are used for manufacturing LEDs, depending on the required radiation spectrum and field of application. Basically, they differ in the type of radiation (direct or luminiferous), semiconductor material and packaging technology (Dzhigadlo et al., 2005; Pronina, 2003; Zheng et al., 2019). Table 1 shows the available colours and voltage drops depending on the materials used. In order to reveal the sensitivity of plants to certain spectral components of light, lamps were made using LEDs of various emitted spectra. Table 2 shows the characteristics of the manufactured luminaires.

Table 1. Design features of LEDs.

\begin{tabular}{lcc}
\hline Material / Technology & Colour / Wavelength & Voltage drop, V \\
\hline Gallium Arsenide (GaAs) & Infrared 870 nm & 1.42 \\
Aluminium Gallium Arsenide (AlGaAs) & Infrared, red 621-870 nm & $1.42-2.0$ \\
Gallium Phosphide (GaP). Depending on alloying & Red, orange, yellow, green & $2.0-2.5$ \\
Gallium Nitride India (InGaN) & Blue, purple 400-460 nm & $2.6-3.2$ \\
Aluminium Gallium Nitride (AlGaN) & Ultraviolet 250-320 nm & $2.8-4.2$ \\
Combination of blue, green and red LEDs (RGB) & White or wide range colour & \\
Gallium Nitride India (InGaN) + luminophore & Various shades of white, red & $2.6-3.2$ \\
\hline
\end{tabular}

Table 2. LED equipment parameters.

\begin{tabular}{lcc}
\hline Name & Supply voltage/current consumption & Wavelength \\
\hline GL36D36R & $33 \mathrm{~V} 0.7 \mathrm{~A}$ & $660 \mathrm{~nm}$ \\
GL48D36RW & $42 \mathrm{~V} 0.65 \mathrm{~A}$ & $635 \mathrm{~nm} 4000 \mathrm{~K}$ White \\
GL48D36B & $43 \mathrm{~V} 0.65 \mathrm{~A}$ & $450 \mathrm{~nm}$ \\
GL36D36RB & $39 \mathrm{~V} 0.7 \mathrm{~A}$ & $450 \mathrm{~nm} 660 \mathrm{~nm}$ \\
GL48D36F & $41 \mathrm{~V} 0.65 \mathrm{~A}$ & Phyto White \\
GL48D36RB & $43 \mathrm{~V} 0.65 \mathrm{~A}$ & $635 \mathrm{~nm} 450 \mathrm{~nm}$ \\
\hline
\end{tabular}

As can be seen from the table, LEDs of red $(660 \mathrm{~nm}, 635$ $\mathrm{nm}$ ), blue (450 $\mathrm{nm}$ ) and white (ordinary $4000 \mathrm{~K}$ lighting and phytodiodes, developed specifically for plant growing, were used. As a result of combining these LEDs, 
the study obtained a spectrum from monochrome red and blue (GL36D36R and GL48D36B luminaires) to almost full spectrum luminaires (GL48D36RW and GL48D36F). To determine the sensitivity of plants to the intensity of illumination, the luminaires were divided into groups. Each group contained 10 and 18 luminaires of the same type. Luminaires were mounted on metal stands at a height of $300 \mathrm{~mm}$ from the apical bud of rooted cuttings.
Plants and lamps were placed in separate hotbeds to maintain the microclimate. The lamps were powered from power sources located in sealed cabinets outside the greenhouses. There were also timers for turning on and off the lighting according to a given programme. A control group was located in a separate hotbed without additional lighting (Figure 2).

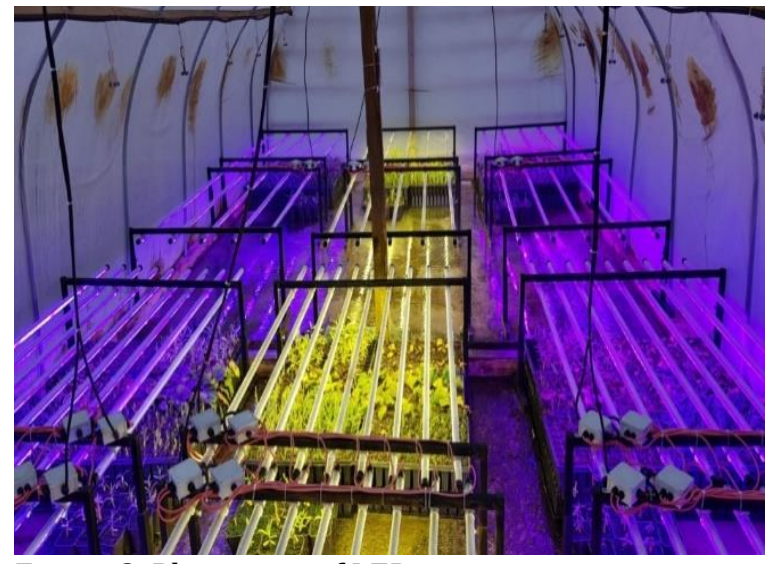

Figure 2. Placement of LED equipment.

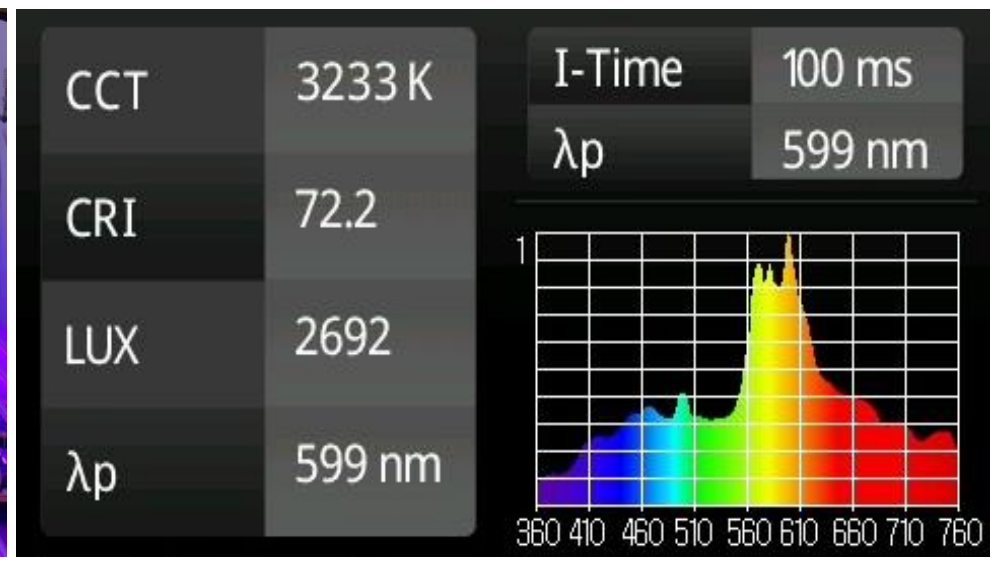

Figure 3. Spectral composition of lighting in control group.
Two types of conifers were selected for propagation by cutting - savine juniper (Juniperus sabina L.) and creeping juniper (Juniperus horizontalis Moench), evergreen - common box (Buxus sempervirens L.), shrubs - Japanese spiraea (Spiraea japonica Lf), Amur maple (Acer ginnala (Maxim.), Siberian dogwood (Swida alba L.) (including cultivar "Spaethii"), as well as white willow (Salix alba L.) cultivar - "Olympiisky Ogon", and brittle willow (Salix fragílis L.) cultivars - "Basfordiana" (Salix fragilis "Basfordiana") and "Bullata" (Salix fragilis "Bullata"). The installed LED equipment was examined to identify the spectral features. Measurements for Table 3 were made with UPRtek MK350 spectrometer at the level of plant apical buds ( $300 \mathrm{~mm}$ from the luminaire) in groups with 18 luminaires. For comparison, Figure 3 shows the measurement results in a group without additional lighting.

The characteristic emission spectrum of sodium lamps is visible. In addition to the spectrum, an important indicator is the energy efficiency of lighting equipment. To obtain correct comparison results for different types of luminaires, the current consumed by them was adjusted to the same value $-650 \mathrm{~mA}$ per device. This allowed assessing the sensitivity of plants to a certain spectrum of illumination without correcting for its intensity. The presence in each of the six spectral groups of luminaires of two subgroups with different radiation intensities allowed identifying the most energy efficient solution, as well as to assess the effect of radiation intensity on plant development. To assess the effectiveness of rooting on the 54th day from the beginning of the experiment, a detailed phytopathological examination was carried out (Arefiev, 2000; Arefiev and Petrov., 1993; Partolin and Partolina., 2006). All cuttings of all types and forms of decorative woody plants were taken into account. The assessment was carried out according to the following gradations: 1 - healthy (without signs of leaf diseases, damage to buds, stems), 2 - with leaf diseases (spots, necrosis, scab, mould, rust, deformation), 3 - with diseases of stem areas (necrosis, cancers, tracheomycosis, rot). 


\begin{tabular}{|c|c|c|c|c|c|c|c|c|c|}
\hline \multirow{7}{*}{ GL48D36RB } & \multicolumn{4}{|c|}{ 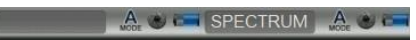 } & \multirow{7}{*}{ GL48D36B } & \multirow{3}{*}{ CCT } & \multicolumn{3}{|c|}{$A \bullet \approx$ SPECTRUM A $A=$} \\
\hline & CCT & $\mathrm{OK}$ & I-Time & $12 \mathrm{~ms}$ & & & $0 \mathrm{~K}$ & \multirow{2}{*}{$\begin{array}{l}\text { I-Time } \\
\lambda p\end{array}$} & \multirow{2}{*}{$\begin{array}{l}6 \mathrm{~ms} \\
448 \mathrm{~nm} \\
\end{array}$} \\
\hline & \multirow{2}{*}{ CRI } & \multirow{2}{*}{0.0} & \multicolumn{2}{|c|}{$\lambda \mathrm{p} \quad 464 \mathrm{~nm}$} & & & \multirow{2}{*}{0.0} & & \\
\hline & & & \multirow{2}{*}{\multicolumn{2}{|c|}{ 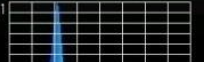 }} & & CRI & & & 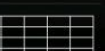 \\
\hline & LUX & 3397 & & & & LUX & 4044 & \multirow{2}{*}{ 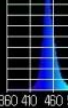 } & 3 \\
\hline & $\lambda p$ & $464 \mathrm{~nm}$ & \multicolumn{2}{|c|}{ 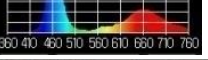 } & & \multirow[t]{2}{*}{$\lambda p$} & $448 \mathrm{~nm}$ & & +3 \\
\hline & & $A$ & SPECTRL & A e = & & & A er & $\begin{array}{l}30040405 \\
\text { SPECTR }\end{array}$ & 8060607070700 \\
\hline \multirow{6}{*}{ GL48D36F } & CCT & $3469 \mathrm{~K}$ & I-Time & $26 \mathrm{~ms}$ & \multirow{6}{*}{ GL48D36RW } & CCT & $3694 \mathrm{~K}$ & \multirow{3}{*}{$\begin{array}{l}\text { I-Time } \\
\lambda p\end{array}$} & \multirow{3}{*}{$\begin{array}{l}35 \mathrm{~ms} \\
453 \mathrm{~nm}\end{array}$} \\
\hline & & & & $582 \mathrm{~nm}$ & & \multirow{2}{*}{ CRI } & & & \\
\hline & CRI & 70.1 & \multirow{4}{*}{\multicolumn{2}{|c|}{ 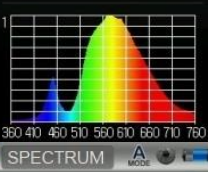 }} & & & 95.2 & & \\
\hline & LUX & 16880 & & & & LUX & 10620 & \multirow{2}{*}{ (1) } & +2 \\
\hline & $\lambda p$ & $582 \mathrm{~nm}$ & & & & $\lambda p$ & $453 \mathrm{~nm}$ & & \multirow{2}{*}{$\frac{\sqrt{30061060070780}}{A-20}$} \\
\hline & & A 2 & & & & & $A \in$ & $\begin{array}{l}504040205 \\
\text { SPECTR }\end{array}$ & \\
\hline \multirow{5}{*}{ GL36D36RB } & $\mathrm{CCT}$ & OK & \multirow{3}{*}{$\lambda p$} & \multirow{3}{*}{$\begin{array}{l}8 \mathrm{~ms} \\
452 \mathrm{~nm}\end{array}$} & \multirow{5}{*}{ GL36D36R } & CCT & $0 \mathrm{~K}$ & \multirow{2}{*}{$\begin{array}{l}\text { I-Time } \\
\lambda p\end{array}$} & \multirow{3}{*}{$\begin{array}{l}8 \mathrm{~ms} \\
663 \mathrm{~nm}\end{array}$} \\
\hline & & & & & & & & & \\
\hline & CRI & 0.0 & & & & CRI & 0.0 & 10 & \\
\hline & LUX & 2962 & & & & LUX & 3910 & & \\
\hline & $\lambda p$ & $452 \mathrm{~nm}$ & & te & & $\lambda p$ & $663 \mathrm{~nm}$ & & \\
\hline
\end{tabular}

\section{RESULTS AND DISCUSSION}

As evidenced by the findings of a continuous detailed phytopathological examination and an indispensable laboratory analysis, on all affected leaves of all types and forms of the tested plants, the causative agent of the disease (mould) was Botrytis cinerea Pers., a fungus from the division Deuteromycota (Imperfect fungi), order Melanconiales, which causes grey mould. For the development of this fungus, a sufficiently high relative humidity of the air is required, which is fully satisfied by the experimental conditions. The causative agent of this mold under normal conditions is saprophyte, under very favourable conditions - facultative parasite (S.S et al., 2019; Teodorescu et al., 2011).

Analysing the data obtained reveals those different types of plants during the autumn harvesting of cuttings demonstrate very different resistance to leaf mould and stem rot, despite absolutely identical cultivation conditions. Obviously, the evergreen gymnosperms junipers and evergreen box - were completely unaffected by the identified pathogen, their leaves and stems were absolutely healthy against a very high infectious background, surrounded by almost entirely diseased deciduous angiosperm plant species. The explanation for this is quite obvious - by the beginning of October, the leaves of deciduous species are already extremely old, worn out, and their immune potential is fully developed. For the saprophyte Botrytis cinerea Pers. such leaves represent an excellent readily available food substrate, which it certainly takes advantage of. In willows, spiraea, dogwood, all old leaves were completely affected by grey mould. The Amur maple has been affected by $86-89 \%$.

In a hotbed of a greenhouse complex, a rapidly developing saprophyte with a bias towards facultative parasitism begins to infect the axial organs with secondary integumentary tissues - the stems of cuttings of those plant species that are very difficult to root by woody cuttings or do not root at all, especially those that go into dormancy at the end of the growing season. This fully applies to Japanese spiraea (92-95\% stem rot, i.e. death) and Amur maple (about 5\%). In dogwood and, especially, willows, the rooting ability is significantly higher, but their stems on the 54th day of cultivation rot by $2-8 \%$, and young leaves on fresh growths become mouldy by 3 to 13\% (Dobiáš and Havlíček, 2020; Elad et al., 2011; Shaikh et al., 2018).

The differences in the spectral composition of the used luminous flux in different variants of the experiment and control were not influenced on all the dependences established in the course of the study. Those insignificant fluctuations in the intensity of the lesion from variant to variant are of a random nature and are not statistically significant. The results obtained allowed substantiating recommendations for: a) prevention of leaf mould with grey mould and stem rot by disinfecting greenhouse premises, equipment, inventory, tools, substrate components and compliance with industrial sanitation and personal hygiene measures during work; b) regularity of planned phytopathological examinations 
(at least once every two weeks); c) the use of fungicides or biological products to combat the identified infection (Abbas et al., 2019).

Particular attention was paid to the success of the rooting of cuttings. The first results were obtained in the course of autumn cutting during the rooting of fastgrowing species - willow and Siberian dogwood. Both species of plants and their cultivars participated in the experiment. A complex of rooting success indicators was studied, of which, according to the study, the following indicators are the most informative - sprout length $(\mathrm{cm})$, average root length $(\mathrm{cm})$, number of roots (pcs.). Table 4 shows the results of rooting of white willow cuttings, depending on the illumination type.

Table 4. Results of rooting cuttings of white willow (Olympiisky Ogon cultivar).

\begin{tabular}{lccc}
\hline \multirow{2}{*}{ Luminaire type } & \multicolumn{3}{c}{ White willow (Olympiisky Ogon cultivar) } \\
\cline { 2 - 4 } & Shoot length, cm & Number of roots, pcs. & Average root length, cm \\
\hline GL48D36RB & 3.51 & 7.0 & 5.75 \\
GL48D36F & 1.52 & 5.5 & 5.25 \\
GL36D36RB & 2.16 & 3.5 & 3.35 \\
GL48D36B & 4.25 & 9.5 & 9.13 \\
GL48D36RW & 2.35 & 6.0 & 3.25 \\
GL36D36R & 2.12 & 6.5 & 5.13 \\
control & 6.11 & 10.5 & 5.51 \\
\hline
\end{tabular}

Table 5. Results of rooting cuttings of brittle willow (Basfordiana cultivar).

\begin{tabular}{lccc}
\hline \multirow{2}{*}{ Luminaire type } & \multicolumn{3}{c}{ Brittle willow (Basfordiana cultivar) } \\
\cline { 2 - 4 } & Shoot length, cm & Number of roots, pcs. & Average root length, cm \\
\hline GL48D36RB & 4.88 & 8.7 & 4.38 \\
GL48D36F & 3.01 & 7.8 & 4.91 \\
GL36D36RB & 7.60 & 14.1 & 5.29 \\
GL48D36B & 3.96 & 9.6 & 3.68 \\
GL48D36RW & 6.03 & 11.1 & 4.66 \\
GL36D36R & 4.51 & 7.9 & 4.23 \\
control & 3.89 & 11.6 & 3.27 \\
\hline
\end{tabular}

Table 6. Results of rooting cuttings of brittle willow (Bullata cultivar).

\begin{tabular}{lccc}
\hline \multirow{2}{*}{ Luminaire type } & \multicolumn{3}{c}{ Brittle willow (Bullata cultivar) } \\
\cline { 2 - 4 } & Shoot length, cm & Number of roots, pcs. & Average root length, cm \\
\hline GL48D36RB & 4.66 & 6.9 & 4.13 \\
GL48D36F & 1.53 & 7.5 & 3.38 \\
GL36D36RB & 5.62 & 6.6 & 3.35 \\
GL48D36B & 1.23 & 5.0 & 3.17 \\
GL48D36RW & 4.02 & 7.2 & 4.81 \\
GL36D36R & 1.81 & 7.0 & 1.24 \\
control & 3.53 & 9.5 & 3.44 \\
\hline
\end{tabular}

According to the complex of the studied indicators, the rooting of white willow cuttings was most successful with a combination of blue and red light of LED equipment. There was also the advantage of more intense blue LEDs fixtures on rooting formation. The influence of the red spectrum LEDs was most pronounced in the stem growth. Table 5 and Table 6 show the results of rooting cuttings of various brittle 
willow cultivars. In the Basfordiana willow, in terms of a set of indicators, the most effective was the illumination of blue - red and red - white combinations of LED equipment and the same most effective influence this combination caused on the course of stem growth.

In the Bullata willow, analysis of a set of indicators showed the greatest success of rooting with lamps of intense full spectrum and intense red - white combinations of LED. However, the growth of the stem was more influenced by illumination of blue - red spectrum combinations and also by the intense red white combinations of LED. Rooting of Siberian dogwood was slower; however, the first results are obtained (Table 7 and Table 8).

Table 7. Results of rooting cuttings of Siberian dogwood.

\begin{tabular}{lccc}
\hline \multirow{2}{*}{ Luminaire type } & \multicolumn{3}{c}{ Siberian dogwood } \\
\cline { 2 - 4 } & Shoot length, cm & Number of roots, pcs. & Average root length, cm \\
\hline GL48D36RB & 1.81 & 7.9 & 1.43 \\
GL48D36F & 0.79 & 5.12 & 1.35 \\
GL36D36RB & 1.81 & 6.6 & 1.50 \\
GL48D36B & 1.97 & 5.4 & 1.10 \\
GL48D36RW & 1.04 & 6.5 & 1.31 \\
GL36D36R & 2.25 & 7.0 & 1.24 \\
control & 0.87 & 4.7 & 0.86 \\
\hline
\end{tabular}

The growth of sprouts Siberian dogwood and the complex of indicators of the development of the root system most influenced by the LED equipment of blue - red spectrum combinations and the intensive type red spectrum. This tendency was also revealed for the Spaethii cultivar of Siberian dogwood (Table 8).

Table 8. Results of rooting cuttings of Siberian dogwood (Spaethii cultivar).

\begin{tabular}{lccc}
\hline \multirow{2}{*}{ Luminaire type } & \multicolumn{3}{c}{ Siberian dogwood (Spaethii cultivar) } \\
\cline { 2 - 4 } & Shoot length, cm & Number of roots, pcs. & Average root length, cm \\
\hline GL48D36RB & 2.06 & 6.7 & 2.15 \\
GL48D36F & 0.87 & 5.5 & 1.38 \\
GL36D36RB & 1.60 & 7.1 & 0.95 \\
GL48D36B & 1.41 & 5.1 & 1.30 \\
GL48D36RW & 1.38 & 6.1 & 1.00 \\
GL36D36R & 0.67 & 8.6 & 1.50 \\
control & 0.83 & 8.9 & 0.58 \\
\hline
\end{tabular}

The growth of sprouts of the Spaethii cultivar of Siberian dogwood is most intense of blue - red spectrum combinations of LED. To assess the prospects for the introduction of LED lamps in crop production, a project was carried out to re-equip the greenhouse area with them. For the calculations, the following initial data were taken:

- suspension height of lamps above plants - $0.3 \mathrm{~m}$;

- area - 60×12 $\mathrm{m}^{2}$;

- number of modules (prefabricated modules for mounting lamps) - 16 pcs;

- distance between modules - $1 \mathrm{~m}$;
- the number of lamps used - 168 pcs. (28 pcs. per line).

AGR0144_Standart luminaires with a 600W HPS sodium lamp were considered as replaceable luminaires. The initial parameters for the lighting design were assumed to be as follows:

- efficiency of the AGRO-144_Standart luminaire 0.6 ;

- luminous flux of the DNaT lamp - $88.500 \mathrm{~lm}$;

- power consumption of the lamp - $648 \mathrm{~W}$;

- level of illumination on the surface of the plant installation - 11.000 lux; 
- lamp life 20.000 hours.

The project envisaged replacing the existing $600 \mathrm{~W}$ generator lamps with $166 \mathrm{~W}$ LED lamps. The spectrum of lamps was closest to the absorption spectrum of plants. Its design is simple and reliable. The modular design of the luminaire allows it to be used for various types of greenhouses. An example of a cost-benefit analysis for this project is shown in Table 9. The main advantage of LED lighting for this project is the selection of an almost ideal radiation spectrum for plant growth. Notably, the low power consumption of LEDs is approximately identical in light characteristics, one LED lamp consumes three times less electricity than a conventional sodium lamp. At the same time, LEDs have a long service life (100.000 hours), which provides a long warranty period (7 years) and a long service life (10 years) of the LED lamp. As for LED lamps, it should be especially noted that they are environmentally friendly and have no problems with disposal. These properties are conditioned by the fact that there are no harmful substances in LEDs. In addition, they do not heat up as much during operation as other lamps, which makes easier to maintain the required climatic conditions when growing plants.

Table 9. Technical-economic of the use of LED luminaires with power consumption of $166 \mathrm{~W}$.

Technical-economic calculation of replacement of lamps (DNaT600) in a greenhouse

\begin{tabular}{lcc}
\hline Input parameters & Lamp & LEDs \\
Light source/luminaire type & DNaT600 & DNaT600 \\
Light source power consumption, $\mathrm{W}$ & 600 & 144 \\
Power consumption of the luminaire, $\mathrm{W}$ & 648 & 166 \\
Working hours per day, hour & \multicolumn{2}{c}{$\mathbf{2}$} \\
Electricity consumed per day, kW*hour & 9.72 & 365 \\
Number of days in a year & \multicolumn{2}{c}{-} \\
Number of lamps in the luminaire & 168 & 168 \\
Number of luminaires & 1 & 0 \\
Number of lamp replacements per year, times & - & 7 \\
Warranty period of operation, years & \multicolumn{2}{c}{7} \\
\hline
\end{tabular}

The disadvantages of LED lighting include the relatively large size of the lamps, which is associated with the desire to achieve a higher emission intensity due to the larger number of LEDs, and the relatively high cost of lamps at the initial stage. The first drawback is not critical for conventional greenhouses, and the second is compensated by a short payback period (about 2.5 years) and a rather long service life. After that, the purchase price has already been paid in full and the savings are increased due to the low power consumption of LED lamps. It is fair to say that the disadvantage associated with the size of the LED lamp is not significant when using such lamps in modern automated greenhouses. The environmental friendliness of LED lamps and the absence of problems with their disposal are of particular note. These characteristics endorse that there are no harmful substances in LEDs. In addition, they do not heat up as much during operation as other lamps, which makes easier to maintain the necessary climatic conditions when growing plants.

\section{CONCLUSIONS}

Modern greenhouses are complex technical complexes, mostly robotic. They are controlled by automated systems, into which it is quite natural to add brightness control, both in intensity and in the spectral composition of radiation, and perform such control actions according to programmes that take into account the stages of plant development. Unlike other lamps, LEDs are not fragile, so devices based on them can be stable, do not contain toxic substances, the possibility of low voltage current makes them fire safe. All this makes LED lamps extremely attractive for use for greenhouse lighting. With the advent of cadmium-free quantum dots, a new wave of LED lighting technology has emerged.

At the first stage of the study, the installation of LED equipment was carried out to conduct experiments on the year-round rooting of cuttings of decorative woody plants. The spectral features of lighting installations of various intensities have been studied to identify the most energy-efficient option. Phytopathological 
monitoring of the experiment was carried out. Biometric studies have revealed the influence of spectral features on the success of rooting cuttings of various decorative woody plants in the autumn. These results indicate the importance of using LED lamps for plant illumination. Modern LEDs cover the entire visible range of the optical spectrum, from red to violet. Thus, by combining LEDs of different colour groups, it is possible to obtain a light source with almost any spectral composition in the visible range. Other advantages of LEDs should be noted, such as low power and therefore low energy consumption of LED-based devices. Of particular note is the long service life of LEDs, which is about 50.000 hours. It provides a long warranty period for the LED device, which is 7 years, and a long service life of 10 years, at least several times longer than the lamp life, which makes the use of LEDs extremely cost effective. The power of the LED depends on the current flowing in the crystal. This provides control over the radiant power of the LED lamp with the use of the current switch.

\section{REFERENCES}

Abbas, A., S. U. Khan, W. U. Khan, T. A. Saleh, M. H. U. Khan, S. Ullah, A. Ali and M. Ikram. 2019. Antagonist effects of strains of Bacillus spp. against Rhizoctonia solani for their protection against several plant diseases: Alternatives to chemical pesticides. Comptes Rendus Biologies, 342: 124-135.

Arefiev, Y. F. 2000. Genetic and ecological aspects of forest phytopathology. Voronezh State Academy of Forestry and Technologies, Voronezh.

Arefiev, Y. F. and S. A. Petrov. 1993. Some genetic and ecological aspects of forest protection. In: Genetic and ecological foundations of increasing forest productivity. IFGTB, Voronezh, pp. 100-10.

Bakharev, I., A. Prokofiev, A. Turkin and A. Yakovlev. 2019. Application of LED lamps for lighting greenhouses: reality and perspective. Modern Automation Technologies, 2: 76-82.

Dobiáš, R. and V. Havlíček. 2020. Chromoblastomycosis and phaeohyphomycosis, overlooked fungal diseases. Klinicka Mikrobiologie a Infekcni Lekarstvi, 26: 54-61.

Dzhigadlo, E. N., M. I. Dzhigadlo and L. V. Golyshkina. 2005. Methodical recommendations on the use of biotechnological methods in working with fruit, berry and ornamental crops. SNU VNII, Oryol.
Efremova, S. Y., E. G. Kulikova, V. V. Konovalov and E. I. Tikhomirova. 2020. Modelling the effect of artificial lighting on plant growth. E3S Web of Conferences, 161: 01114.

Elad, Y., L. Shpialter, D. Rav David, U. Yermiahu, I. Dori, L. Ganot, D. Shmuel, E. Matan, Y. Messika, R. Levite and S. Pivonia. 2011. SUPPRESSION OF GRAY MOLD IN LISIANTHUS BY PASSIVE MEANS OF GREENHOUSE ENVIRONMENT MANAGEMENT. Acta Horticulturae: 1277-1283.

Kozlowski, T. T. and S. G. Pallardy. 2002. Acclimation and Adaptive Responses of Woody Plants to Environmental Stresses. The Botanical Review, 68: 270-334.

Morrow, R. C. 2008. LED lighting in horticulture. HortScience, 43: 1947-1950.

Nissim-Levi, A., M. Kitron, Y. Nishri, R. Ovadia, I. Forer and M. Oren-Shamir. 2019. Effects of blue and red LED lights on growth and flowering of Chrysanthemum morifolium. Scientia Horticulturae, 254: 77-83.

Partolin, I. V. and O. P. Partolina. 2006. Phytosanitary condition of some dendroflora intoducents in Borisoglebsk. In: Introductions that grows in botanical gardens and arboretums: Materials of the International Scientific Conference. LLC "YugoVostok, LTD", Donetsk, pp. 367-71.

Pronina, I. N. 2003. Microclonal reproduction of actinidia kolomikt. In: V. A. Gudkovskiy, Ye. P. Kuminov, T. V. Zhidokhina, V. Yu. Skripnikov, M. A. Popov, L. A. Shchekotova, O. S. Akulova, S. V. Gubarev (Eds.), Condition and development prospects of nontraditional horticultural crops: Materials of the International Scientific-Methodical Conference. Kvarta, Voronezh, pp. 235-37.

Pyatih, A., A. Selivanova, N. Kartashoval and E. Tikhonova. 2019. Greening of the administrativeterritorial structures in the urban space. IOP Conference Series: Earth and Environmental Science, 226: 012011.

Robert, C. 2018. Morrow LED lighting in horticulture. HortScience, 43: 1947-1950.

S.S, M., M. S.M, I. A.V and S. V.E. 2019. Economic Prospects of Innovative Technologies of In Vitro Cultivation of Seedlings. International Journal of Economics and Business Administration, VII: 439446. 
Selivanova, A. and N. Kartashova. 2016. Evaluation of green space of the natural system of Voronezh. Proceedings of the Saint-Petersburg Forest Engineering Academy, 217: 45.

Shaikh, S., A. K. Tripathy, G. Gill, A. Gupta and R. Hegde. 2018. Monitoring Chili Crop and Gray Mould Disease Analysis Through Wireless Sensor Network. Advances in Intelligent Systems and Computing. Springer International Publishing, p. 924-931.

Teodorescu, T. I., W. Guidi and M. Labrecque. 2011. The use of non-dormant rods as planting material: A new approach to establishing willow for environmental applications. Ecological Engineering, 37: 1430-1433.

Teodoronskiy, V. and G. Zherebtsova. 2010. Landscaping of residential areas in town-planning aoundations. Publishing House "Academia", Moscow.

Zheng, J., F. Ji, D. He and G. Niu. 2019. Effect of Light Intensity on Rooting and Growth of Hydroponic Strawberry Runner Plants in a LED Plant Factory. Agronomy, 9: 875.

Publisher's note: EScience Press remains neutral with regard to jurisdictional claims in published maps and institutional affiliations.

Open Access This article is licensed under a Creative Commons Attribution 4.0 International License, which permits use, sharing, adaptation, distribution and reproduction in any medium or format, as long as you give appropriate credit to the original author(s) and the source, provide a link to the Creative Commons license and indicate if changes were made. The images or other third-party material in this article are included in the article's Creative Commons license, unless indicated otherwise in a credit line to the material. If material is not included in the article's Creative Commons license and your intended use is not permitted by statutory regulation or exceeds the permitted use, you will need to obtain permission directly from the copyright holder. To view a copy of this license, visit http://creativecommons.org/licenses/by/4.0/. 